\title{
The effect of Jaycustomer misbehaviour on the Mehrabian-Russell model
}

\author{
Dr. Hao-Te, LU $1^{\text {st }}$ \\ Department of Business Administration \\ Tainan University of Technology \\ Tainan, Taiwan
}

Yi-Chou Wang* $3^{\text {rd }}$

Department of International Business Management

Tainan University of Technology

Tainan, Taiwan

t90063@mail.tut.edu.tw

\author{
Dr. Pi-Yueh, Cheng $2^{\text {nd }}$ \\ Department of Finance \\ Tainan University of Technology \\ Tainan, Taiwan
}

\begin{abstract}
While the Mehrabian-Russell model has been widely discussed in service research, no attempt has been made to identify moderating factors for this model. The current study provides a more comprehensive view in an attempt to explore the impact of an exogenous variable on the model. A personally administered questionnaire was designed for patrons of themed restaurants. Overall, 265 responses were collected and used in this study. As expected, customers' emotional responses mediate the relationship between atmosphere and customers' behavioural intentions. Although this study cannot prove that jaycustomer misbehaviours have a negative moderating effect on the model, it is still possible to produce some interesting arguments.
\end{abstract}

Keywords-Mehrabian-Russell Model; Atmospherics, Emotional Response, Behavioural Intention, Themed Restaurant, Jaycustomer

\section{INTRODUCTION}

Empirical findings have acknowledged that the physical environment plays an important role in the formation of a customer's emotional response (Bitner, 1992; Ezeh and Harris, 2007; Lin and Worthley, 2011; Mehrabian and Russell, 1974; Turley and Milliman, 2000). Positive perceptions of the physical environment have a positive effect on perceived service quality (Kim and Moon, 2009; Reimer and Kuehn, 2005; Zeithaml et al., 1996), customer satisfaction (AubertGamet, 1997; Sulek and Hemsley, 2004; Wakefield and Blodgett, 1994), and behavioural intention (Ryu and Jang, 2008 ) in a service environment, and eventually lead to loyalty (Turley and Milliman, 2000).

The Mehrabian-Russell (M-R) model is one of the most well-known models used to explain the effects of the physical environment on customers' behaviour (Liu and Jang, 2009). Prior research has also tested the effect of a number of moderating variables on the Mehrabian-Russell model. Among those variables were such as personal factors, situational factors, expectations (Chen et al., 2005; Foxall and Yani-de-Soriano, 2005), frequency of visits, expectations from previous visits (Ryu and Han, 2011), and so forth. Although prior research offers a rich set of insights for managerial practices, the extant research ignore misbehaviours from jaycustomers that may affect it. For example, customers' behavioural intentions may be influenced by misbehaviour from other customers. Such misbehaviours include cutting the line, speaking loudly, smoking, public inebriation, and acting in an abusive manner toward staff or other patrons. Those who exhibit such behaviours are termed jaycustomers (Harris and Reynolds, 2004; Lovelock, 1994). Bitner et al. also (1994) identified four types of "problem customer" behaviours in service environments. They are rule breakers who cut the line, drunken customers, and those who act uncooperatively and abusively toward employees or other patrons. Therefore, it is necessary to consider that environmental stimuli may lead to a heightened emotional state, or may foster other exogenous factors that can affect the final behavioural response. Hence, we investigated this relationship by extending the M-R model and using jaycustomer misbehaviour as an exogenous factor. The exogenous factor may have a moderating effect on the model.

We used themed restaurants as the target research subject, for several reasons. First, the restaurant industry has become more competitive and customers have developed higher expectations. More specifically, the fundamental variables in restaurants include not only the food, quality, and service, but also the physical environment, or ambience (Kotler, 1973). Second, as suggested by Jang and Namkung (2009, p.455) that "emotional experiences elicited by service industry-specific stimuli may be more important in full-service restaurants than in fast-food or limited-service restaurants". Third, there is little relevant research dedicated to themed restaurants, because the number of such restaurants has increased rapidly since the mid 1990s. This type of restaurant is designed to provide customers not only with a meal but also with a special atmosphere and an exciting dining experience. According to Weissa et al. (2005), customers are more satisfied by the atmosphere rather than by the novelty this kind of restaurant provides. Therefore, the M-R model is ideal for application to themed restaurants. Overall, pertinent studies have identified that a positive dining atmosphere in a service environment has a positive effect on customers' behavioural intentions (Lam et al., 2011; Ryu and Jang, 2008 and 2007). 
However, jaycustomers and their dysfunctional behaviours are prevalent in daily life and affect other customers' consumption experiences (Harris and Reynolds, 2003; Lovelock, 1994). Previous research has indicated that misbehaviours from jaycustomers have negative effects on customers' overall perceptions and evaluations of their experiences in a service environment (Harris and Reynolds, 2003). Moreover, Huang (2008) suggested that dysfunctional behaviours from other patrons may affect customer behaviour, but this supposition requires further research. Accordingly, we examined the relationships among the physical environment, emotional responses of customers, misbehaviours of jaycustomer, and the relative behavioural intentions in themed restaurants.

To this end, we proposed a conceptual model by modifying the M-R environmental psychology model. More specifically, we examined the effects of the physical environment on behavioural intentions via emotional responses, the effects of jaycustomer misbehaviour on the relationship between emotional responses and behavioural intentions, and the moderating effects of jaycustomer misbehaviour on the relationship between emotional responses and behavioural intentions. This template, modified in MS Word 2007 and saved as a "Word 97-2003 Document" for the PC, provides authors with most of the formatting specifications needed for preparing electronic versions of their papers. All standard paper components have been specified for three reasons: (1) ease of use when formatting individual papers, (2) automatic compliance to electronic requirements that facilitate the concurrent or later production of electronic products, and (3) conformity of style throughout a conference proceedings. Margins, column widths, line spacing, and type styles are built-in; examples of the type styles are provided throughout this document and are identified in italic type, within parentheses, following the example. Some components, such as multi-leveled equations, graphics, and tables are not prescribed, although the various table text styles are provided. The formatter will need to create these components, incorporating the applicable criteria that follow.

\section{LITERATURE REVIEW AND THEORETICAL FRAMEWORK}

\section{The M-R model}

Since Kotler (1973) proposed the term "atmospherics," defined as the effects of physical stimuli on consumer behaviour, a number of papers have discussed the effects of atmosphere on customer behaviour in service settings (Bitner, 1992; Turley and Milliman, 2000). Similarly, environmental psychologists Mehrabian and Russell (1974) proposed a model to explore the effects of the physical environment on customer behaviour through an S-O-R paradigm. Accordingly, the M-R model includes three parts: environmental stimuli (S), emotional response $(\mathrm{O})$, and behavioural intention $(\mathrm{R})$. Their study indicates that environment stimuli can influence a customer's emotional response, which refers to the choice a customer makes in either approaching or avoiding an environment. Moreover, the emotional response mediates the relationship between environmental stimuli and the customer's behavioural intention. Although the model was not primarily designed to describe explore customer's behaviour, it is applicable to various consumption settings (Countryman and Jang, 2006; Liu and Jang, 2009; Ryu and Jang, 2007).

\section{Atmospherics}

Atmospherics is defined as the act of consciously designing the service environment to produce specific emotional effects on the customer to enhance their purchasing probability (Kotler, 1973). Bitner (1992) indicated that atmospherics contains three dimensions: "ambience", "spatial layout and functionality", and "signs, symbols, and artifacts". This includes both tangible features (e.g., specifically designed buildings or inter-decorations) and intangible features (e.g., music, odor, lighting, and temperature), which comprise multiple elements of the service environment that may influence both customers and employees (Ezeh and Harris, 2007; Hoffman and Turley, 2002; Bitner, 1992). Customers are more likely to make a judgement on the tangible features in the service environment. Such situations are particularly applicable to patrons in restaurants (Levitt, 1981).

The ambience has a positive association with the perceived service quality and can elicit a pleasurable feeling (Kim and Moon, 2009). Examples of spatial layout and functionality include entrances, exits, seats, or walkways that are wellarranged (Bitner, 1992). These are key factors that may affect the comfort of the customer (Harris and Ezeh, 2008). The signs, symbols, and artifacts refer to the interior decoration (Lam et al., 2011). Bitner (1992, p.66) indicated that "many items in the physical environment serve as explicit or implicit signals that communicate about the place to its users". Interior decoration could present a very important communicative medium to customers. Lin (2004) reported that customers are always based on visual elements to make judgments and evaluations of properties in the hospitality industry. Overall, the longer the customers stay in a service environment, the better the physical environment they expect.

\section{Emotional responses}

Emotional responses are measured on the pleasure, arousal, and dominance (PAD) scale in the original M-R model. Mehrabian and Russell (1974, p.55) described that "a person's feeling at any time can be characterised by three dimensions in our framework (e.g., pleasure, arousal, dominance)". Pleasure is defined as feelings of happiness or joy. Arousal refers to feelings of excitement and stimulation. Dominance is the degree to which a person feels influential, in control, or important. Bagozzi et al. (1999) pointed out that the virtues of the PAD scale are intuitive and easy to understand. Nevertheless, Liu and Jang (2009) mentioned some limitations regarding its applicability. First, the scale is not originally designed to explore the emotional responses; researchers are incapable of knowing the true emotions, such as joy or happiness, that are being experienced by customers from the scale alone. Second, it uses binary items. It is difficult for customers to present their emotions in either a positive or negative extreme (Babin et al., 1998). Therefore, Liu and Jang (2009) suggested using eight basic emotions proposed by Plutchik (1980) to measure emotional responses, which 
include joy, acceptance, expectancy, surprise, fear, anger, sadness, and disgust. However, in terms of themed restaurants, it can be assumed that the properties are designed with a pleasant dinning environment in mind. Therefore, we used only positive emotions to measure emotional response.

\section{Effects of atmospherics on emotional responses}

Empirical studies have demonstrated that atmospherics can influence customers' emotions in a service setting. For instance, the music played in retail stores has a significant impact on a variety of consumer behaviours such as sales volume, time spent shopping, and so forth (Turley and Milliman, 2000). Music is used not only to stimulate emotions and mood (Chebat et al., 1995; Ryu and Jang, 2007) but also to affect purchasing intentions (Areni and Kim, 1993; Baker et al., 1992). Overall, previous studies centered on the service sector have indicated that the use of music can affect customer perceptions of the place, relaxation and satisfaction, increase or decrease overall shopping time (Hui et al., 1997; Magnini and Parker, 2009; Mattila and Wirtz, 2001; Yalch and Spangenberg, 2000). In addition, color, lighting, smell, temperature, and spatial layout can all influence customers' emotional responses (Areni and Kim, 1993; Chebat and Michon, 2003; Hui et al., 1997; Lin, 2004; Morrin and Ratneshwar, 2003; Turley and Milliman, 2000). Based on a review of the atmospherics literature, this study hypothesises that:

H1. Dining atmospherics have a positive effect on emotional response.

\section{Effects of emotional responses on behavioural intention}

It is important to understand customers' emotional responses because they may affect final behavioural intention. Emotional responses include three subjects; they are pleasure, arousal, and dominance. Pleasure is a powerful factor influencing approach -avoidance behaviour in shops, which includes the inclination of a customer to spend more time and money than anticipated. Arousal can interact with pleasure, which means that customers increase their approaching behaviours in a pleasant environment and avoidance behaviours in an unpleasant environment (Donovan et al., 1994). Mehrabian and Russell (1974, p.30) also explained that "an individual's preference for an environment is closely related to his or her preferred arousal level, and no matter what level of pleasure he starts with, he is likely to prefer situations where pleasure is enhanced". However, it has been shown that a non-significant relationship between dominance and customers' behaviour exists (Donovan et al., 1994).

Furthermore, behavioural intention has been defined as "the degree to which a person has formulated conscious plans to perform or not perform some specified future behaviour" (Warshaw and Davis, 1985, p.214). Researchers have identified that behavioural intention refers to the patron's willingness or unwillingness to re-purchase, to purchase more, and to recommend the store to others in the future (Baker et al., 2002; Hightower, 2010, Hightower et al., 2002). Overall, both pleasure and arousal have direct effects on behavioural intention (Ryu and Jang, 2007). The preceding discussion leads to the following hypotheses:
H2: Emotional responses have positive effects on behavioural intention.

\section{Jaycustomers moderate the M-R model}

The service environment is often a complex phenomenon that includes various elements (Shostack, 1987). Customers' emotional responses may stem not only from atmospherics and/or interactions with employees but also from the behaviours of other customers when they are in close proximity to one another (Shostack, 1987; Martin and Pranter, 1989). Lovelock (1994) coined the term "jaycustomer", defining them as "those who deliberately act in a thoughtless or in an abusive manner, causing problems for the firm, employees, or other customers" (Harris and Reynolds, 2004, p.339). The misbehaviours of jaycustomers can result in extremely negative consumption experiences for other customers (Huefner and Hunt, 2000). Such customer-tocustomer interactions can lead to the development of transactional dissatisfaction (Harris and Reynolds, 2004). Consequently, this study supposes that misbehaviours from jaycustomers lead the surrounding customers to experience negative emotions, which in turn affects those customers' final behaviour. It can be hypothesised that:

H3. Misbehaviours from jaycustomers negatively moderate the relationship between emotional response and behavioural intention.

According to the articulated hypotheses, this study proposes an extended M-R model as shown in Figure 1. The model shows the relationships among atmospherics, emotional response, customer misbehaviour, and behavioural intention. Jaycustomer misbehaviour is treated as an exogenous variable, or a moderator that may affect the M-R model.

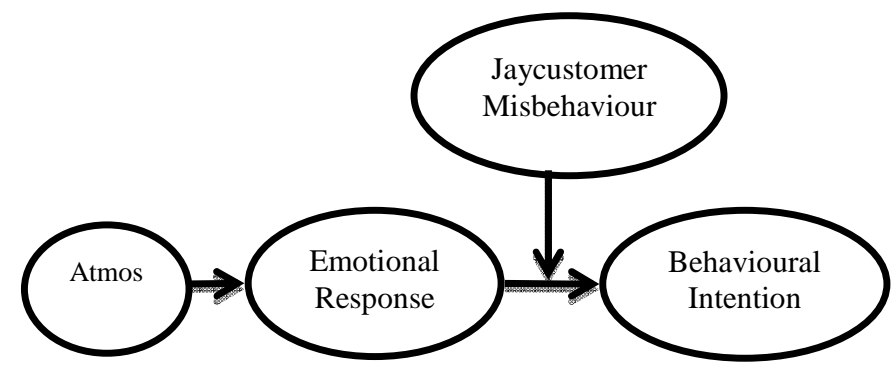

Figure 1: A conceptual framework of M-R model and jaycustomer misbehaviour

\section{Methodology}

Based on the research methodology literature, a quantitative research methodology is the most appropriate to investigate the topics included in this study. Accordingly, a survey instrument was created. The survey was limited and undertaken in themed restaurants. 


\section{Measurement}

A personally administered questionnaire was formulated to test the hypotheses. The instrument contained five sections: atmospherics, emotional response, jaycustomer misbehaviour, behavioural intentions, and participants' personal information. The instrument was largely derived from the existing body of literature on the subject areas. We also followed the suggestion of Bentler and Chou (1987) that there should be at least three measures within each construct. A total of five atmospherics-related items articulated by Bitner (1992) were used with some modifications. These five items were also utilised in previous research to test the effects of atmospherics on behavioural intention (Jang and Namkung, 2009; Wakefield and Blodgett, 1994, 1996). Next, a total of six attributes of positive emotional responses were selected, following the scale developed by Izard (1977). The descriptions of these six emotions were also adopted to test the effects of emotional response on behaviours by Liu and Jang (2009). Behavioural intention has often been seen as a component of loyalty, and in this regard we followed the work of Zeithaml et al. (1996) by adapting their scale. At the same time, we measured participants' perceived negative consumption experiences as they related to misbehaviours from jaycustomers. The misbehaviours were operationalised using four items derived from Bitner et al. (1994) and Grove and Fisk (1997). The operationalised items used to test the hypotheses can be found in Appendix A. The respondents were asked to indicate their level of agreement with a given statement on a scale ranging from (1) strongly disagree to (7) strongly agree. Finally, the questionnaire also requested participants' personal peofile, such as gender, age, occupation, academic level, and dining motivation.

\section{Data collection}

Using a convenience sampling approach, data were collected from two themed restaurants offering exotic food and service in Taiwan. Questionnaires were randomly distributed to customers waiting to be served, or those who had already finished dining. The survey was conducted over 5 consecutive weeks, and only in the evening. Therefore, both weekday and weekend dinner customers were surveyed. Nevertheless, it is not always possible to meet a jaycustomer in a restaurant. Therefore, subjects were asked to imagine one or more jaycustomers in the restaurant, or to recall previous experiences. In total, 300 customers were requested to complete a questionnaire on a voluntary basis. A total of 265 data were collected and used.

\section{Data analysis}

Following the suggestions by Anderson and Gerbing (1988), a two-step approach was conducted. First, a confirmatory factor analysis (CFA) took place in order to determine whether the observed variables reflected the hypothesised latent construct by testing the model fit and path significance, with the reliability also checked by observing Cronbach's alpha. Convergent and discriminate validity were examined by checking factor loadings and average variance extracted (AVE). After confirming the measurement model, the structural model was examined to identify the relationships among constructs. Finally, this study utilised structural equation modeling (SEM) using Mplus 6 modeling software to analyse the moderating effect on the M-R model.

\section{ANALYSIS AND RESULTS}

\section{Descriptive statistics}

The results of the respondents' characteristics and dining profiles are articulated below. Among the 265 respondents, females accounted for $52 \%(n=137)$ and males accounted for $48 \%(\mathrm{n}=128)$ of the sample. Most respondents were 23-30 years old $(n=89)$ and $63 \%$ were aged 23-40 $(n=167)$. The survey participants had a relatively high education level. In particular, over half had graduated from university $(51 \%$, $\mathrm{n}=135)$. The three major occupations were general clerical workers in offices $(33 \%)$ followed by students $(19 \%)$ and service workers (17\%). Finally, their top three primary motivations for dining at a themed restaurant were for social occasions $(50 \%)$, to have a special and authentic experience $(20 \%)$, and to enjoy flavorful food (15\%).

\section{Measurement model}

We assessed reliability and validity for each measure using confirmatory factor analysis (CFA). As shown in Table 1, most scales exhibited desirable psychometric properties for all constructs. For example, although the composite reliability (CR) of misbehaviours was lower than the cutoff value of .70 (Hair et al., 2010), a CR of 0.69 was observed. The CR values of the other three constructs were above the cutoff value (range 0.828 to 0.891), indicating adequate internal consistency for multiple items of each construct (Hair et al., 2010). In addition to misbehaviours, the AVE of all constructs exceeded 0.5 , indicating that a large proportion of the variance was explained by the constructs (Fornell and Larcker, 1981; Hair et al., 2010). Therefore, we demonstrate another way to test convergent and discriminate validity of misbehaviours. Table 2 shows the relationships between latent variables obtained from the principal components analysis and each related item. The values in the table are high, and move in the expected direction, which suggests an acceptable level of convergent validity. The correlation coefficients presented in Tables 1, 2 and 3 suggest that discriminate validity exists because "correlation patterns within constructs differ from the correlation patterns among constructs, suggesting that the measures have an acceptable level of discriminate validity" (Ryu et al., 2008, p.465).

Table 1: Mean, composite reliabilities, and scale information.

\begin{tabular}{lrrrr} 
& \multicolumn{1}{c}{ Mean } & \multicolumn{1}{c}{ SD } & CR & AVE \\
\hline 1-ATMO & 5.589 & .72448 & .828 & .503 \\
2-ER & 5.829 & .76409 & .889 & .573 \\
3-BI & 5.052 & 1.22897 & .891 & .733 \\
4-JAY & 2.031 & .60005 & .692 & .360
\end{tabular}

ATMO: Atmospherics; ER: Emotional responses; BI: Behavioural intention; JAY: Jaycustomer misbehaviour 
Table 2: Correlations and AVE

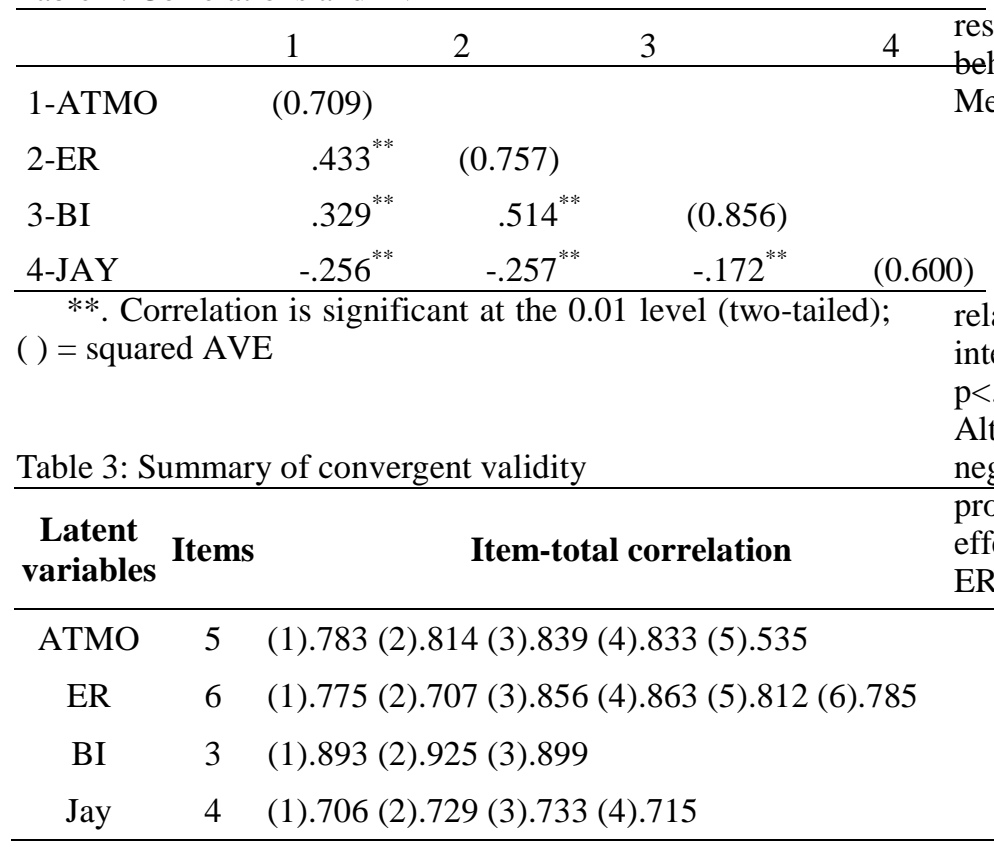

\section{Results of the M-R model}

Next, the MR model was estimated. The estimation produced the following statistics: $\chi 2(74)=146.544, \mathrm{p}<$ $0.001, \chi 2 / \mathrm{df}=1.98$; root mean square error of approximation $=$ 0.061 ; confirmatory fit index $=0.962$; Tucker-Lewis index $=$ $0.953 ;$ SRMR $=0.041$. The estimated model was therefore a good fit to the data.

With regard to the hypotheses, the results showed strong support for the proposed effects. Figure 2 depicts the standardised path coefficients. First, the results confirmed a positive relationship between atmospherics and customer emotional response $(\beta=.41, \mathrm{t}=5.20, \mathrm{p}<.001)$; therefore, dining atmospherics have a positive effect on emotional responses, supporting $\mathrm{H} 1$. In accordance with $\mathrm{H} 2$, customer emotional responses also had a positive effect on behavioural intention $(\beta=.99, \mathrm{t}=5.16, \mathrm{p}<.001)$.

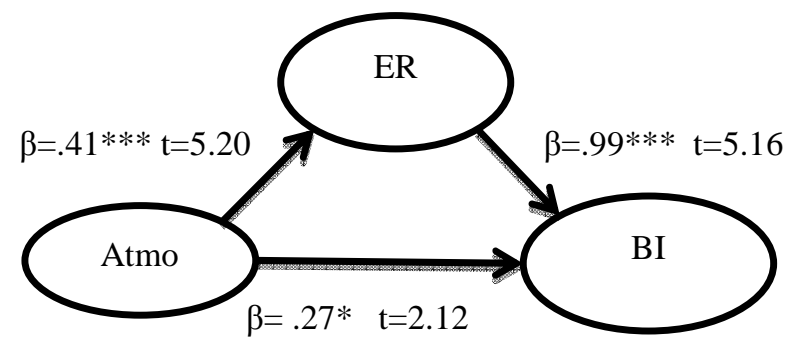

Figure 2: The main effects on MR Model

Furthermore, as shown in Figure 2, the three conditions proposed by Baron and Kenny's (1986) were satisfied in the model. This indicates that emotional responses have a partial mediating role on atmospherics and behavioural intention. This implies that the effects of atmosphere on consumer behavioural intention are mediated by the consumer's emotional response (Mehrabian and Russell, 1974). It also follows that atmospherics influence customers' emotional responses, which in turn affects customers' approach behaviours towards the environment (Liu and Jang, 2009; Mehrabian and Russell, 1974; Wakefield and Baker, 1998 ).

\section{Moderating effects}

relationship between emotional response and behavioural intention was supported; however, it was positive $(\beta=1.09$, $\mathrm{p}<.05)$, as shown in Figure 3. Thus, H3 was not supported. Although the misbehaviours did not have a significant negative moderating effect on the M-R model, it can still be proposed that jaycustomer misbehaviours have a negative effect on the MR model. For example, the t-values of BI for $\mathrm{ER}$ and for the Jay $\times$ ER interaction were 4.64-2.47.

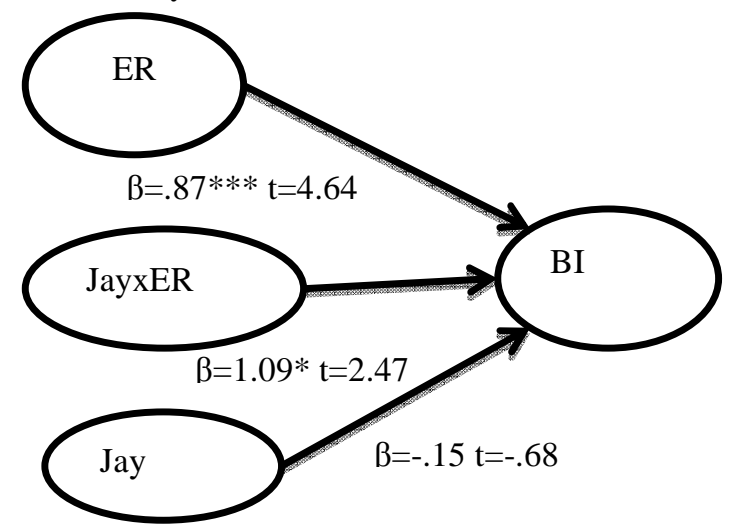

Figure 3: The moderated effect on M-R

$$
* \mathrm{p}<0.05, * * \mathrm{p}<0.01, * * * \mathrm{p}<0.001
$$

\section{DISCUSSION AND IMPLICATION}

\section{Theoretical implications}

The review of extant research on the M-R model is central to understanding the importance of the physical environment in a service setting. The role of environmental stimuli is unquestionably important in hospitality research. From a theoretical perspective, the first contribution of this study stems from the successful operationalisation of a three-facet measure based on the original perspective of the M-R model (Mehrabian and Russell, 1974) in themed restaurants in Chinese society. The parameter estimates of the structural equation model confirm that perceptions of atmospherics can affect customer behavioural intentions via the creation of positive emotions (Jang and Namkung, 2009).

While this model has been extensively commended, no attempt has been made to identify jaycustomers misbehaviour as moderating factors. Thus, this work provides a more comprehensive view of the effects of an exogenous variable on the model. The second contribution centers on the lack of a demonstration of a moderating effect, i.e., our results indicate that some external factors (in this case, jaycustomer behaviour) cannot change consumers' behavioural intentions in a service environment. The atmospherics do, however, 
intensely affect customers' emotional responses and subsequently influence their behaviours.

\section{Managerial implications}

Aside from the theoretical implications, three managerial implications are also proposed. First, according to the experiences of patrons in themed restaurants, high-quality atmospherics generally encourage favorable behaviours. This provides managers of themed restaurants a better understanding of the importance of internal atmospherics and how they can elicit positive emotional responses and eventually affect customers' behavioural intentions. Themed restaurants in particular are designed to give patrons a special and unforgettable experience (Weissa et al., 2005). Hence, managers of themed restaurants should aim to improve atmospherics.

Another managerial implication is that emotional responses appear to mediate the relationship between atmospherics and behavioural intentions. The importance of positive emotions indicates that customers should be given pleasant sensations in restaurants. Overall, it can be suggested that restaurant managers, as well as those in other hospitality areas, should pay more attention to improving atmospherics and creating environmental stimuli to elicit positive emotions.

Finally, although the effects of jaycustomer misbehaviour on the behavioural intentions of other patrons were not significant in this study, restaurant managers should not ignore the potential negative influence of these misbehaviours that other studies have reported, for instance Harris and Reynolds (2004).

\section{Limitations and further research}

This study also had several limitations, which provide fruitful avenues for further research. First, we did not clearly classify "smoking versus non-smoking customers" or "drinking (alcohol) versus non-drinking customers". Although the term jaycustomer was proposed by Lovelock (1994) and the misbehaviours were defined by Bitner et al. (1994) and Grove and Fisk (1997), it is difficult to give misbehaviour a distinct definition. For example, a smoker may not agree that smoking in a restaurant is misbehaviour. Further studies on jaycustomer misbehaviours could divide respondents into two groups, smokers and non-smokers, drinkers and non-drinkers. Second, the data collected from customers in themed restaurants can hardly capture the real relationship between restaurants and customers overall. Themed restaurants are designed to be special and exciting, and customers may be very motivated and excited for a particular reason in this kind of restaurant; therefore, external factors may not have an amplified effect on the relationship. Further research can investigate jaycustomers in greater detail and how their behaviour affects others in different types of hospitality spaces.

Third, since the study is are mainly examining the effect of jaycustomers on others customers, themed restaurants may not suitable. The statistical result has partially proved this, since themed restaurants tend to attract customers with similar interests and consuming ability. It is less likely for people who share this much in common to irritate and annoy each other in the restaurants, compared to other types of restaurants. Further research should also consider the types of restaurants and customers.

Fourth, while the conceptualisation of the M-R model is well established in hospitality research, few empirical studies have investigated moderating effects on the model. We assessed the potential moderating effects of jaycustomer misbehaviour on the model. Future research could address other potential moderators such as switching cost, poor wordof-mouth reviews, negative corporate social responsibility or reputation, and so forth. On the other hand, further research could also perhaps demonstrate the jaycustomer in different ways. For example, if jaycustomers really have a negative effect on customers' emotional responses, these instances can be categorised as service failures. Service recovery is the action a service provider takes in response to a service failure (Hart et al., 1990). Therefore, further research could also consider measures of service recovery, if Jay-customers have had a negative effect on the behaviours of other patrons.

Fifth, most M-R model research has focused on the assumption that good atmospherics lead to a positive emotional response in customers, which then contributes to positive customer behaviour. Further research could discuss how the M-R model works in the opposite direction, for instance, whether poor atmospherics produce negative emotions in customers and lead to negative behavioural intentions (Mattila and Ro, 2008).

\section{REFERENCES}

[1] Anderson, J. C. \& Gerbing, D. W. (1988). Structural modeling in practice: a review and recommended two-step approach. Psychological Bulletin, 103(3), 411-423.

[2] Aubert-Gamet, V. (1997). Twisting servicescape: Iversion of the physical environment in a re-appropriation process. International Journal of Service Industry Management, 8(1), 26-41.

[3] Areni, C. S. \& Kim, D. (1993). The influence of background music on shopping behavior: Classical versus Top-Forty music in a wine store. Advances in Consumer Research, 20, 336-340.

[4] Bagozzi, R. P., Gopinath, M. \& Nyer, P. U. (1999). The role of emotions in marketing. Journal of the Academy of Marketing Science, 27(2), 184-206.

[5] Babin, B. J., Darden, W. R. \& Babin, L. A. (1998). Negative emotions in marketing research: affect or artifact? Journal of Business Research, 42(3), 271-285

[6] Baker, J., Levy, M. \& Grewal, D. (1992). An experimental approach to making retail store environmental decisions. Journal of Retailing, 68(4), 445-460.

[7] Baker, J., Parasuraman, A., Grewal, D. \& Voss, G. (2002). The influence of multiple store environment cues on perceived merchandise value and patronage intentions. Journal of Marketing, 66(2), 120-141.

[8] Baron, R. M. \& Kenny, D. A. (1986). The moderator-mediator variable distinction in social psychological research: conceptual, strategic, and statistical considerations. Journal of Personality and Social Psychology, 51(6), 1173-1182.

[9] Bentler, P. M. \& Chou, C. P. (1987). Practical issues in structural modeling. Sociological Methods \& Research, 16(1), 78-87.

[10] Bitner, M. J. (1992). Servicescapes: The impact of physical surroundings on customers and employees. Journal of Marketing, 56(2), 57-71.

[11] Bitner, M. J., Booms, B. H. \& Mohr, L. S. (1994). Critical service encounters: the employee's viewpoint. Journal of Marketing, 58(4), 95106. 
[12] Chebat, J. C., Filatrault, P., Gelinas-Chebat, C. \& Vaninsky, A. (1995). Impact of waiting attribution and consumer's mood on perceived quality. Journal of Business Research, 34(3), 191-196.

[13] Chebat, J. C. \& Michon, R. (2003). Impact of ambient odors on mall shoppers' emotions, cognition, and spending. Journal of Business Research, 56(7), 529-539.

[14] Chen, A., Peng, N. \& Hung, K. P. (2015). The effects of luxury restaurant environments on diners' emotions and loyalty: Incorporating diner expectations into an extended Mehrabian-Russell model. International Journal of Contemporary Hospitality Management, 27(2), 236-260.

[15] Countryman, C. C. \& Jang, S. C. (2006). The effects of atmospheric elements on customer impression: the case of hotel lobbies. International Journal of Contemporary Hospitality Management, 18(7), 534 - 545

[16] Donovan, R. J., Rossiter, J.R. \& Nesdale, A. (1994). Store atmosphere and purchasing behavior. Journal of Retailing, 70(3), 283-294.

[17] Ezeh, C. \& Harris, L. C. (2007). Servicescape research: a review and a research agenda. The Marketing Review, 7(1), 59-78.

[18] Fornell, C. \& Larcker, D. (1981). Evaluating structural equation models with unobservable variables and measurement error. Journal of Marketing Research, 18(1), 39-50.

[19] Foxall, G. R. \& Yani-de-Soriano, M. M. (2005). Situational influences on consumers' attitudes and behavior. Journal of Business Research, 58(4), 528-525.

[20] Grove, S. J. \& Fisk, R. P. (1997). The impact of other customers on service experiences: a critical incident examination of getting along. Journal of Retailing, 73(1), 63-85.

[21] Jang, S. C. \& Namkung. Y. (2009). Perceived quality, emotions, and behavioral intentions: Application of an extended Mehrabian-Russell model to restaurants. Journal of Business Research, 62(4), 451-460.

[22] Hair, J. F., Black, W. C., Babin, B. J. \& Anderson, R. E. (2010). Multivariate Data Analysis: A Global Perspective. London: Pearson.

[23] Harris, L. C. \& Ezeh, C. (2008). Servicescape and loyalty intentions: an empirical investigation. European Journal of Marketing, 42(3/4), 390422.

[24] Harris, L. C. \& Reynolds, K. L. (2004). Jaycustomer behaviour: an exploration of types and motives in the hospitality industry. Journal of Service Marketing, 18(5), 339-357.

[25] Harris, L. C. \& Reynolds, K. L. (2003). The consequences of dysfunctional customer behavior. Journal of Service Research, 6(2), 144-161.

[26] Hart. C. W., Heskett, J. L. \& Sasser, W. E. (1990). The profitable art of service recovery.

[27] Harvard Business Review, 68(4), 148-156.

[28] Hightower, R. (2010). Commentary on conceptualizing the servicescape construct in a study of the service encounter in eight countries. Marketing Management Review, 2(1), 76-86.

[29] Hightower, R., Brady, M. K. \& Baker, T. (2002). Investigating the role of the physical environment in hedonic service consumption: An exploratory study of sporting events. Journal of Business Research, 55(9), 697-707.

[30] Hoffman, K. D. \& Turley, L. W. (2002). Atmospherics, service encounters and consumer decision making: an integrative perspective. Journal of Marketing Theory and Practice, 10(3), 33-47.

[31] Huang, W. H. (2008). The impact of other-customer failure on service satisfaction. International Journal of Service Industry Management, 19(4), 521-536.

[32] Huefner, J.C. and Hunt, K.H. (2000). Consumer retaliation as a response to dissatisfaction. Journal of Consumer Satisfaction Dissatisfaction and Complaining Behavior, 13, 61-82.

[33] Hui, M. K., Dube, L. \& Chebat, J. C. (1997). The impact of music on consumers' reaction to waiting for services. Journal of Retailing, 73(1), 87-104.

[34] Izard, C. E. (1977), Human emotions. New York: Plenum.

[35] Kim, W. G. \& Moon, Y. J. (2009). Customers' cognitive, emotional, and actionable response to the servicescape: a test of the moderating effect of the restaurant type. International Journal of Hospitality Management, 28(1), 144-156.

[36] Kotler, P. (1973). Atmospherics as a marketing tool. Journal of Retailing, 49(4), 48-64.

[37] Lam, L. W., Chan, K. W., Fong, D. \& Lo, F. (2011). Does the look matter? The impact of casino servicescape on gaming customer satisfaction, intention to revisit, and desire to stay. International Journal of Hospitality Management, 33(2), 558-567.

[38] Levitt, T. (1981). Marketing intangible products and product intangibles. Harvard Business Review, 59(3), 94-102.

[39] Lin, I. Y. (2004). Evaluating a servicescape: the effect of cognition and emotion. International Journal of Hospitality Management, 23(2), 163178.

[40] Lin, I. Y. \& Worthley, R. (2011). Servicescape moderation on personality traits, emotions, satisfaction, and behaviors. International Journal of Hospitality Management, 31(1), 31-42.

[41] Liu, Y. H. \& Jang, S. C. (2009). The effects of dining atmospherics: An extended Mehrabian-Russell model. International Journal of Hospitality Management, 28(4), 494-503.

[42] Lovelock, C.H., (1994), Product Plus: How Product + Service = Competitive Advantage. New York: McGraw-Hill.

[43] Magnini, V. P. \& Parker, E. E. (2009). The psychological effects of music: Implications for hotel firms. Journal of Vacation Marketing, 15(1), 53-62.

[44] Martin, C. L. \& Pranter, C. A. (1989). Compatibility management: customer-to-customer relationships in service environments. Journal of Service Marketing, 3(3), 6-15.

[45] Mattila, A.S. \& Wirtz, J. (2001). Congruency of scent and music as a driver of in-store evaluations and behavior. Journal of Retailing, 77(2), 273-289.

[46] Mattila,A. S. and Ro, J. (2008). Discrete negative emotions and customers dissatisfaction response in a casual restaurant setting. Journal of Hospitality \& Tourism Research, 32(1), 89-101.

[47] Mehrabian, A. \& Russell, J. (1974), An Approach to Environmental Psychology. Cambridge, Massachusetts: Massachusetts Institute of Technology.

[48] Morrin, M. \& Ratneshwar, S. (2003). Does it make sense to use scents to enhance brand memory? Journal of Marketing Research, 41(1), 0-25.

[49] Plutchik, R. (1980). Emotion: A psychoevolutionary synthesis. New York: Harper \& Row.

[50] Reimer, A. \& Kuehn, R. (2005). The impact of servicescape on quality perception. European Journal of Marketing, 38(7/8), 785-808.

[51] Ryu, K. \& Han, H. (2011). New or repeat customers: How does physical environment influence their restaurant experience? International Journal of Hospitality Management, 30(3), 599-611.

[52] Ryu, K. \& Jang, S. (2008). Influence of restaurant's physical environments on emotion and behavioral intention. The Service Industries Journal, 28(8), 1151-1165.

[53] Ryu, K. \& Jang, S. (2007). The effect of environmental perception on behavioral intentions through emotions: the case of upscale restaurant. Journal of Hospitality and Tourism Research, 31(1), 56-72.

[54] Ryu, K., Han, H. \& Kim, T. H. (2008). The relationships among overall quick-casual restaurant image, perceived value, customer satisfaction, and behavioral intentions. International Journal of Hospitality Management, 27(3), 459-469.

[55] Shostack, G. L. (1987). Service positioning through structural change. Journal of Marketing, 51(1), 34-43.

[56] Sulek, J. M. \& Hensley, R. L. (2004). The relative importance of food, atmosphere and fairness of wait. The Cornell Hotel and Restaurant Administration Quarterly, 45(3), 235-247.

[57] Turley, L. M. \& Milliman, R. E. (2000). Atmospheric effects on shopping behavior: A review of the experimental evidence. Journal of Business Research, 49(2), 193-211.

[58] Wakefield, K.L. \& Blodgett, J.G. (1996). The effect of the servicescape on customers' behavioural intentions in leisure service settings. Journal of Services Marketing, 10(6), 45-61. 
[59] Wakefield, K. L. \& Blodgett, J. G. (1994). The important of servicescapess in leisure service settings. Journal of Service Marketing, 8(3), 66-76.

[60] Wakefield, K.L. \& Baker, J. (1998). Excitement at the mall: determinants and effects on shopping response. Journal of Retailing, 74(4), 515-539.

[61] Wakefield, K. L. \& Blodgett, J. G. (1994). The important of servicescape in leisure service settings. Journal of Service Marketing, $8(3), 66-76$

[62] Warshaw, P. R. \& Davis, F. D. (1985). Disentangling behavioral intention and behavioral expectation. Journal of Experimental Social Psychology, 21(3), 213-228.

[63] Weissa, R., Feinsteinb, A. H. \& Dalborc, M. (2005). Customer satisfaction of theme restaurant attributes and their influence on return intent. Journal of Foodservice Business Research, 7(1), 23-41.

[64] Yalch, R. F. \& Spangenberg, E. R. (2000). The effects of music in a retail setting on real and perceived shopping times. Journal of Business Research, 49(2), 139-147.

[65] Zeithaml, V. A., Berry, L. L.\& Parasuraman, A. (1996). The behavioral consequences of service quality. Journal of Marketing, 6(2), 31-46.

Constructs Label Appendix A.

Atmospherics

ATMO1 The facility layout allows me to move around easily.

ATMO2 The interiour design is visually appealing

ATMO3 Colors used create a pleasant atmosphere.

ATMO4 Lighting creates a comfortable atmosphere.

ATMO5 Background music is pleasing.

Emotional responses

ER1 I feel pleasure.

ER2 I feel excitement.

ER3 I feel contentment.

ER4 I feel refreshment.

ER5 I feel relaxation.

ER6 I feel interest.

Behavioural intention

BI1 I would like to come back to this restaurant in the future.

BI2 I would recommend this restaurant to my friends or others.

BI3 I would say positive things about this restaurant to others.

Jaycustomers

J1 I am not happy with rule breaker (e.g. cut in a line).

J2 I am not happy with druken customers.

J3 I am not happy with other customers smoking in the restaurant.

J4 I am not happy other customers abusive manner toward employees or other customers. 